\title{
Polish science 'in need of further reforms'
}

Warsaw. Widespread reforms in the organization of science in Poland, aimed at reducing rigidities in the post-Communist system and increasing incentives for researchers to improve the quality of their work, have been recommended by a panel of science policy experts put together by the Organization for Economic Cooperation and Development (OECD).

In particular, the panel proposes the creation of a fully fledged Ministry for Science, devolving funding responsibilities to a number of research councils, limiting the activities of the Polish Academy of Sciences, and increasing government spending on research and development to one per cent of gross national product (GNP) from its current level of about 0.7 per cent.

The panel also suggests that Poland should abolish the traditional system under which all permanent university staff are required to have a thesis-based second doctorate, known as a habilitated doctor (HD) degree. The "substantial opportunity costs" of this system, it says, are "a major barrier to Polish science becoming internationally competitive."

The OECD review was carried out at the request of the Polish authorities under a procedure that is widely used by the Parisbased agency. Speaking at a meeting in
Warsaw two weeks ago at which the panel's findings were discussed - and whose proceedings will themselves be published together with the report - Aleksander Luczak, Poland's vice-prime minister, said he welcomed the conclusions as "an independent and objective point of view" on Polish science.

The four-member panel gives its general approval to the main thrust of science policy reforms introduced since the end of the communist regime in 1990 (see Nature 372, 593-597; 1994). These have in particular included the creation of a State Committee for Scientific Research (KBN) to focus state support for science.

"[We] believe that the philosophy and competitive principles underlying the system are basically sound," it says, warning against "any moves to relax the existing centralized funding arrangements for science and technology which will

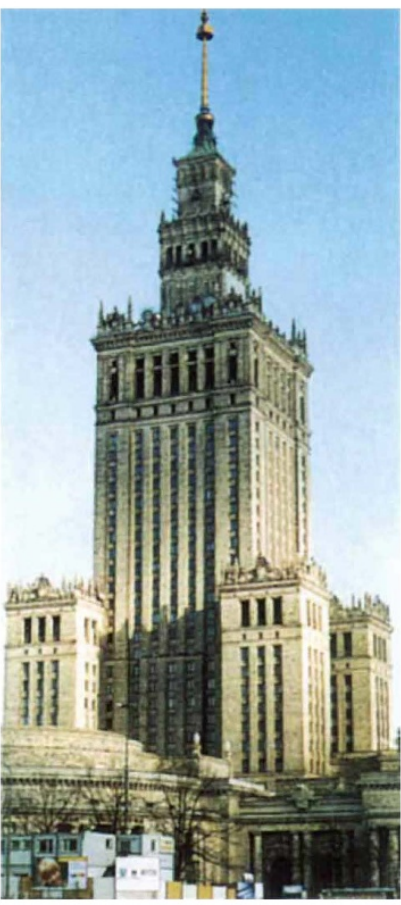

Home of the Polish Academy: are 'unrealistic'. of the universities in a number of areas".

Demands that it should be abolished, says that panel, are therefore "politically unreal-

\section{German research centres take on a historical name}

Bonn. The umbrella group for Germany's 16 federally funded national research centres, which have recently been under pressure to increase their effectiveness, last week announced that it is to adopt a new name. It will also have a new central structure to enable it to play a stronger role in deciding the general strategy of the individual centres.

In line with the German tradition of naming research societies after famous scientists, such as Max Planck and Joseph von Fraunhofer, the body now known as the Arbeitsgemeinschaft der Grossforschungseinrichtungen (AGF, or association of national research centres) will in future be called after one of Germany's best-known scientists, Hermann von Helmholtz.

From November, the AGF will be known as the Hermann von HelmholtzGemeinschaft Deutscher Forschungszentren (HGF), the Helmholtz association of German research centres. The association's chairman, Joachim Treusch, hopes that the image of the nineteenth-century physiologist, physicist and mathematician will be more appealing than the association's present title.

"Our motivation is to signal to the outside world that the national research centres do high quality research and have good collaboration with the whole of the research community," says Treusch.

A better image is certainly needed. The national research centres, whose activities range from research in nuclear safety to plasma physics, have been getting a bad press over the past few years, partly because of their alleged inflexibility - a consequence of the job security enjoyed by most of their scientists.

Criticism flourished in particular during the economic recession that followed reunification, as the centres are expensive to run. Their responsibility to carry out 'big science' or large interdisciplinary programmes means that they often have several thousand scientists.

The centres have recently been under political pressure to improve procedures for assessing the quality of their research, and their budget has not been increased for five years. At the same time, there has also been pressure from industry to make their research more directly relevant to industrial needs (see Nature 372,4 ; 1994).

In response, research centres have cut staff numbers and those centres conducting a high level of applied research agreed last year to include more industrialists on their scientific and supervisory boards.
Behind the scenes, a more sophisticated defence was being planned. The new HGF will be more conscious of the need to let the public know exactly what it stands for: that is, says Treusch, long-term research programmes that are in Germany's general financial or social interests, and which require substantial resources and the willingness to take risks.

In addition, a new senate will be established to steer a coherent general research policy. Its members, who will be announced in November, will include eight ex-officio members representing research organizations, the ministries of research and finance, and the BLK, a body of politicians representing research interests of the federal and state governments.

A further 17 members will be elected from the scientific community, industry and elsewhere. The research centres themselves will not be represented. The head of the Helmholtz association will prepare and lead the senate meetings but will have no voting rights.

The senate will provide general advice on research strategy, oversee the mechanisms for ensuring the quality of research in the centres and promote cooperation both with other centres and with industry.

Alison Abbott 